\title{
Birth distribution in cystic fibrosis in Saguenay-Lac-St-Jean, Quebec, Canada
}

\author{
Jocelyne Daigneault, Gervais Aubin, Fernand Simard, Marc De Braekeleer
}

\begin{abstract}
Although a seasonal trend in the birth distribution has been reported in cystic fibrosis (CF), this finding is still very controversial. The birth distribution of 113 patients with cystic fibrosis born in Saguenay-Lac-St-Jean (complete ascertainment) was analysed using two different statistical methods. Our results showed no monthly or seasonal birth variation. It is likely that a bias owing to incomplete ascertainment might explain why some previous studies found a seasonal trend in the birth distribution of cystic fibrosis.
\end{abstract}

Saguenay-Lac-St-Jean (SLSJ) is a geographically isolated region located 125 miles north-east of Quebec city that was opened to white settlement around 1840. Its population, $98 \%$ French speaking and of Catholic faith, rose from 5000 inhabitants in 1852 to 50000 in 1911 and 285000 today. Several autosomal dominant and recessive disorders have a high prevalence (myotonic dystrophy, cystic fibrosis, etc) while others, frequently found in the SLSJ region and Charlevoix, are almost non-existent elsewhere (spastic ataxia Charlevoix-Saguenay type, polyneuropathy with or without agenesis of the corpus callosum, etc) ${ }^{1}$

Over the past 20 years, monthly or seasonal birth variation has been reported in various chromosomal and congenital anomalies, such as Down's syndrome, Klinefelter's syndrome, and anencephaly. A seasonal trend has also been suggested in cystic fibrosis (CF) by several workers. ${ }^{2-5}$ However, the

Human Genetics, Department of Human Sciences, Université du Québec à Chicoutimi, 555 Boulevard de l'Université, Chicoutimi, Quebec G7H 2B1, Canada.

J Daigneault, $M$ De Braekeleer

Hôpital de Chicoutimi, Chicoutimi, Quebec, Canada. G Aubin, F Simard

Correspondence to Dr De Braekeleer.

Received for publication 20 November 1990.

Revised version accepted for publication 7 February 1991. issue remains controversial since two studies failed to show any uneven monthly birth distribution. ${ }^{67}$

This study was aimed at analysing the monthly birth distribution of patients with cystic fibrosis born in Saguenay-Lac-St-Jean (SLSJ).

\section{Material and methods}

The great majority of the subjects affected with CF living in SLSJ have been followed at the CF clinic in Chicoutimi since spring 1973, the date of its opening. Of a total of 127 CF patients known in the SLSJ region on 31 December 1989, 125 patients had been or were still followed at the CF clinic in Chicoutimi. The diagnosis of cystic fibrosis was based on the patient and family histories, clinical, radiological, and biochemical results. All CF cases were confirmed by at least a positive sweat test. For the present study, only the $111 \mathrm{CF}$ subjects born in SLSJ were considered.

Statistical significance was sought using two methods. The total observed number of patients for each month was compared to the expected number and a $\chi^{2}$ test performed. The expected rates were calculated using all live births in the area during the range of years of birth of the 111 patients (1954 to 1988). For each month, the expected number of patients was calculated using the formula of Nielsen et $a l^{8}$

$$
\mathrm{E}_{\mathrm{m}}=\frac{\mathrm{n}_{\mathrm{m}}}{\mathrm{N}} \times \mathrm{A}
$$

where $E_{m}=$ expected number of patients for a given month,

$\mathrm{n}_{\mathrm{m}}=$ total number of livebirths in a given month in the period studied,

$\mathrm{N}=$ total number of livebirths in the period studied,

$A=$ total number of affected subjects in the period studied.

The second method consisted of a Monte Carlo simulation procedure. The total number of patients was simulated 5000 times under the null hypothesis that the cumulative number of CF births by month should be proportional to the cumulative number of live births by month over the period of study. The probabilities were then determined. 
Number of CF patients born and expected in each month during the study period (1954 to 1988) in the SLSF region.

\begin{tabular}{cccc}
\hline Month No of CF patients & $\begin{array}{c}\text { Mean No of live } \\
\text { births }\end{array}$ & $\begin{array}{c}\text { Expected No of } \\
\text { CF births }\end{array}$ \\
\hline 1 & 14 & 468 & $9 \cdot 2$ \\
2 & 12 & 433 & $8 \cdot 5$ \\
3 & 11 & 517 & $10 \cdot 2$ \\
4 & 11 & 502 & $9 \cdot 9$ \\
5 & 5 & 506 & $10 \cdot 0$ \\
6 & 11 & 458 & $9 \cdot 0$ \\
7 & 10 & 494 & $9 \cdot 7$ \\
8 & 7 & 484 & $9 \cdot 5$ \\
9 & 7 & 499 & $9 \cdot 8$ \\
10 & 7 & 480 & $9 \cdot 4$ \\
11 & 9 & 455 & $8 \cdot 0$ \\
12 & 7 & 447 & $7 \cdot 7$ \\
\hline
\end{tabular}

\section{Results}

The distribution by month of birth of the CF patients was compared to the expected distribution calculated according to the method of Nielsen et al. ${ }^{8}$ The table shows the number of patients born in each month, the mean number of live births by month in the SLSJ region during the period studied (1954 to 1988), and the number of CF births expected by month. As shown in the figure, the frequency of the CF births was markedly increased in January and decreased in May. However, no significant difference was found between the observed and the expected distributions $\left(\chi_{11}^{2}=9.33, p>0.05\right)$. The

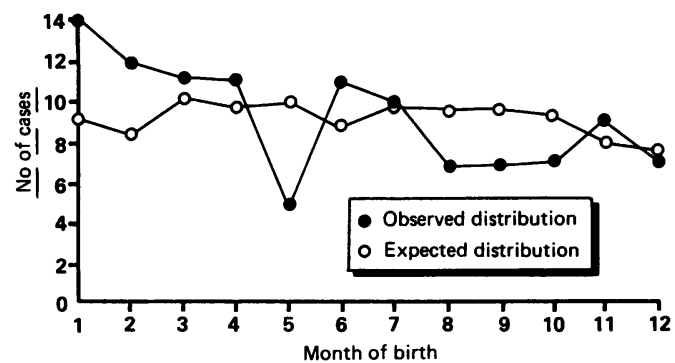

Cumulative monthly distribution of cystic fibrosis in Saguenay-Lac-St-Fean.
Monte Carlo simulations also failed to show any month to have a significantly higher or lower number of CF births than expected ( $p>0.05)$.

Although there was a slight excess of winter births (December to February) over summer births (June to August) (33 compared to 28), the difference was not significant $\left(\chi^{2}=2 \cdot 12, p>0.05\right)$.

\section{Discussion}

No monthly or seasonal trend in the births of the CF patients was found in this series from SaguenayLac-St-Jean. Although there were only 113 cases analysed, this series relies on the fact that all CF patients were born in a well defined region with complete ascertainment. Our results are in agreement with those of David et $\mathrm{al}^{6}$ and Machill et al. ${ }^{7}$

As already suggested by both groups, ${ }^{67}$ it is most likely that the seasonal variation in CF births observed in previously reported series ${ }^{2-5}$ was the result of sampling bias, probably owing to incomplete ascertainment or chance.

This study was supported in part by a grant from the Foundation of the Université du Québec à Chicoutimi. JD was supported by a studentship from the Fonds FCAR.

1 De Braekeleer M. Hereditary disorders in Saguenay-Lac-StJean (Quebec, Canada). Hum Hered (in press).

2 Ten Kate LP. Cystic fibrosis in the Netherlands. Int $f$ Epidemiol 1977;6:23-34.

3 Brackenridge CJ. The seasonal variation of births of offspring from couples heterozygous for cystic fibrosis. Ann Hum Genet 1978;42:197-201.

4 Brackenridge CJ. Bimodal month of birth distribution in cystic fibrosis. Am ₹ Med Genet 1980;5:295-301.

5 Brackenridge CJ. Characteristics of births in each cycle of the bimodal monthly distribution in cystic fibrosis. Am $7 \mathrm{Med}$ Genet 1980;5:303-7.

6 David TJ, Elstow GA, Baumer JH, Evans CM. Cystic fibrosis and the month of birth. $\mathcal{F}$ Med Genet 1981;18:299-300.

7 Machill G, Gedschold J, Kropf S. Birth distribution in cystic fibrosis and phenylketonuria. Eur $\mathcal{F}$ Pediatr 1990;149:406-7.

8 Nielsen J, Petersen GB, Therkelsen AJ. Seasonal variation in the birth of children with aneuploid chromosome abnormalities. Hum Genet 1973;19:67-74. 